Research, part of a Special Feature on Mental Models

\title{
Water Management in the Camargue Biosphere Reserve: Insights from Comparative Mental Models Analysis
}

\author{
$\underline{\text { Raphael Mathevet }}^{1}$, Michel Etienne $^{2}$, Tim Lynam $^{3}{ }^{3}$, and Coralie Calvet $^{1}$
}

\begin{abstract}
Mental models are the cognitive representations of the world that frame how people interact with the world. Learning implies changing these mental models. The successful management of complex social-ecological systems requires the coordination of actions to achieve shared goals. The coordination of actions requires a level of shared understanding of the system or situation; a shared or common mental model. We first describe the elicitation and analysis of mental models of different stakeholder groups associated with water management in the Camargue Biosphere Reserve in the Rhône River delta on the French Mediterranean coast. We use cultural consensus analysis to explore the degree to which different groups shared mental models of the whole system, of stakeholders, of resources, of processes, and of interactions among these last three. The analysis of the elicited data from this group structure enabled us to tentatively explore the evidence for learning in the nonstatute Water Board; comprising important stakeholders related to the management of the central Rhône delta. The results indicate that learning does occur and results in richer mental models that are more likely to be shared among group members. However, the results also show lower than expected levels of agreement with these consensual mental models. Based on this result, we argue that a careful process and facilitation design can greatly enhance the functioning of the participatory process in the Water Board. We conclude that this methodology holds promise for eliciting and comparing mental models. It enriches group-model building and participatory approaches with a broader view of social learning and knowledge-sharing issues.
\end{abstract}

Key Words: ARDI method; consensus analysis; mental models; water management

\section{INTRODUCTION}

Identifying and building social arrangements that are inclusive of the diversity of stakeholders' perceptions, values, and goals has been a key issue in natural resource management (Habermas 1979, Pretty 2003, ComMod 2006). Consequently being able to improve our understanding of stakeholders' mental models-how they represent complex systems - might help the development of mechanisms to improve the use and management of natural resources. The mental model concept is, however, polymorphic. We can find several synonyms or closely related concepts in the social science literature (see Jones et al. 2011), including social representations (Moscovici 1961, Jodelet 2003), social construction of reality (Gumuchian 1991), world view, social thought, and thinking system (Daré 1985).
At the individual level, mental models depend on the social integration of the individual who creates them, their place in the social network, their group membership, their life standards, and interactions (Doise 1985). At the collective level, mental models depend on the way they are designed (i.e., institutions, media). They contribute to the individual's relationship to the world and mediate relations toward other people. A mental model is personal and can be communicated to others through representations (i.e., conceptual models, narratives). Mental models can be defined as the mechanisms that allow human beings "to generate descriptions of system purpose and form, explanations of system functioning and observed system states, and predictions of future system states" (Rouse and Morris 1986). Mental models integrate both knowledge content and structure, they are not fixed, they change and can be 
manipulated, and they help individuals make sense of situations (Johnson-Laird 1983). The degree to which the members of a social group or a team have common knowledge about one specific issue at stake has been referred to as "shared mental models" or "team mental models" (Cannon-Bowers et al. 1993, Klimoski and Mohammed 1994).

Faced with the continuous processes of transformation of our society and all of its institutions, social learning is the aim of several natural resource management and participatory research approaches (Pretty 2003). Human societies and individuals can learn to change. From this perspective, social change is a process of social learning (Bandura 1971, Habermas 1979, Wynne 1992), a process of coordinated learning with cognitive and normative dimensions (Webler et al. 1995). Within a natural resource management organization, the members interact, confront, and change their mental models. They corroborate or change social practice and the associated interpretation of their environment. They collectively and individually learn a new way of thinking and change their initial mental models (Brown et al. 1989, Lave and Wenger 1999).

Within a water resource management context, previous studies have focused mainly on water management conflicts and considered coordination as a key problem (Innes and Booher 1999, Beierle and Cayford 2002, Leach et al. 2002). Others have viewed the main issue as a problem of dialogue on how to share a representation of the functioning of the water management system and how to learn collectively about it (Beierle and Konisky 2000, ComMod 2006). Several authors provide evidence to show that the ways in which stakeholders frame issues can explain collaborative success or failure (Gray 2004, Pahl-Wostl 2006), suggesting that we have to develop processes of social learning and reframing for resolving conflicts. Thus, eliciting mental models in a water resource management context is useful to discuss perceptions and understanding about the structure and cause-andeffect relationships and potential feedback effects of the system representation of the management problem (Hare and Pahl-Wostl 2002, Pahl-Wostl 2006, Daniell 2008). Mental models elicited with specific techniques often serve as a basis from which to develop a conceptual model, and then, a computer model of the system (Doyle and Ford 1998, PahlWostl and Hare 2004, ComMod 2006, Etienne 2009). The process reveals possible differences between the mental models of different actors. A learning organization can be characterized by its members being involved in a process of collaboratively conducted, collectively accountable change directed towards shared aims, values or principles (Watkins and Marsick 1992). A learning organization develops processes and strategies to enhance organizational learning (Argyris and Schön 1978, Argyris 1993). Shared knowledge in team or social organization may enhance the collective organization and performance (Mathieu et al. 2000, Mohammed et al. 2000, Webber et al. 2000), a hypothesis that may have important implications for actions and adaptive management of natural resources. Although application of the concept of mental models is growing, their measurement and analysis remain a challenge (Pahl-Wostl 2006). More investigation is needed that identifies better methodologies for assessing mental models.

We present a new approach to elicit and compare mental models, and we illustrate how it can be used to evaluate social learning that occurred in a specific environmental management body. We build on a research project on water system modeling that gave us the opportunity to study this specific issue in the context of the water management in the Camargue Biosphere Reserve (Appendix 1). A Water Board (Commission exécutive de l'eau) was established to help local stakeholders to identify potential tradeoffs and actions for water management of the central lagoon system (Table 1). If the Water Board is a learning organization according to the definition of Argyris and Schön (1996), we predict three things about the mental models of members and nonmembers of the Water Board: (1) members of the Water Board would have a shared mental model of the water management system; (2) the mental models of the water management system held by members of the Water Board would be different from those held by stakeholders not involved in the Water Board; and (3) mental models of the water management system would converge to a similar one through collective interactions.

We aim to (1) describe the individual mental models of the Water Board members and compare them with nonmember mental models in order to verify whether the Water Board is an arena of social learning on water management in the central delta; (2) discuss these results with respect to the application of a new approach to the elicitation of mental models and the subsequent analysis of these mental models using consensus analysis; and (3) 
Table 1. Socio-professional category of interviewees.

\begin{tabular}{lcc}
\hline \hline & Water Board members & Nonmembers \\
\hline Protected area manager & 3 & 3 \\
Water management association officer & 3 & 3 \\
Hunter & 1 & 3 \\
Stockbreeder (cattle and horses) & 1 & 3 \\
Fisher & 3 & 2 \\
Rice farmer & 3 & 3 \\
Scientist & 2 & 0 \\
Water Officer Regional Agriculture Service & 1 \\
Local Authority Technical Service & 3 \\
Salt Industry Local Director & 1 & 0 \\
Water Officer Regional Natural Park & 0 \\
Director of the Regional Natural Park & 1 & 0 \\
Total & 1 & 0 \\
& $\mathbf{2 3}$ & $\mathbf{1 7}$ \\
\hline
\end{tabular}

discuss what these results mean for the biosphere reserve's management.

\section{METHODS}

A number of approaches to conceptual model building come from system dynamics studies (Hodgson 1992, Vennix 1999, Sterman 2000). Several methods and tools were developed to elicit ontological, relational, and structural knowledge about systems from groups or individuals and integrating these beliefs directly into a graphical model (Hare and Pahl-Wostl 2002). Concept mapping, also called cognitive mapping, is increasingly used in the field of environmental management to elicit individual or collective representations of beliefs as to the structure of a problem to be solved (Eden 1994). Concept maps are personally oriented graphics often used in the initial stages of a research or problem-solving process, in the stage of problem formulation, or to deal with power relationships within a participatory process (Kolmann et al. 2005, ComMod 2006, Dray et al. 2006, Daniell 2008).

To elicit the mental models of each respondent, we used the ARDI method (Etienne 2009) presented in Etienne et al. (2011). This method is often used in the Companion Modeling approach (ComMod 2006) to collectively build a representation of the functioning of a social-ecological system with the main stakeholders. The ARDI method helps to create a shared representation of the key issues and main drivers of the whole system using a common structural framework. The method involves the stakeholders collectively constructing a common model of their system during workshops, which sought to facilitate collective thinking and information sharing on a specific issue. The dialogue process and the collective validation of the model helped to raise the awareness among participants of the different beliefs (technical, lay, or scientific) about the system, hopefully leading to learning (ComMod 2006).

\section{ARDI method and consensus analysis}

This approach is implemented by organizing workshops with stakeholders in which the Actors (stakeholders), Resources, Dynamics (processes), and Interactions (ARDI) that constitute the main drivers and state variables of the social-ecological system are identified and elicited. To do this, the participants collectively answer four questions using system diagrams. The method follows several steps described in Etienne et al. (2011). To be able to compare the mental models of members and nonmembers of the Water Board, we applied this method with individuals drawn from two stakeholder groups: members of the Water Board and nonmembers of the Water Board (Calvet 2008).

Our overarching question was as follows: How would you describe the use and management of 
water in the Central Camargue? This question was split into four specific subquestions to help the respondents formalize the representation of their individual mental models: (1) Who are the main stakeholders that interact with the water and its management in the Central Camargue? (2) What are the main resources related to water in the Central Camargue? (3) What are the main processes that may change the water use and management in the Central Camargue? (4) How does each stakeholder use the resources and change the processes? Each elicitation activity lasted about 2.5 hours and took place at either the interviewee's home or workplace. An example of a completed representation of an individual mental model is shown in Fig. 1.

Consensus analysis (Romney et al. 1986) provides statistical estimates of whether members of a group hold the same beliefs (Horowitz 2009) about a "coherently defined subject matter" (Weller and Romney 1988) or what we will call a knowledge domain. The theory rests on the simple premise that, for a given knowledge domain where a common (socially or culturally defined) truth exists, informant responses are likely to be correlated with this truth to the extent that they know this truth. If, for example, we asked people what fruits grew in their village, the more agreement there was among them, the more confident we could be that their responses were consistent with the underlying and culturally defined truth. Thus, the more an individual's responses are correlated with this underlying truth, the more they know about this knowledge domain. Conversely, if informant responses are not correlated, it is unlikely there is a common truth (problems with sampling and analysis aside). The cultural consensus model uses factor analysis of an individual by individual similarity matrix where similarity is based on the proportion of matches among respondents, corrected for guessing, to questions about the knowledge domain.

Conventionally, there are two steps in the application of consensus analysis (Horowitz 2009). In the first step, elements of the knowledge domain are identified, and in the second step, the relationships of informants to the identified elements of the knowledge domain are assessed using the cultural consensus model. In using the ARDI approach, we combined these two steps; each respondent identified Actor, Resource, Dynamics, and Interaction elements of the knowledge domain. The nature of the questions posed to informants meant this was equivalent to a free listing data collection process. The total set of Actors, Resources, and Dynamics elements identified by all respondents formed the questions (columns) of the data matrix with a 1 in the column for each respondent that identified that element and a 0 otherwise. The consensus analysis module of UCINET (http://www.analytictech.com/ucinet) was used on the raw data matrices for stakeholders, resources, and processes. The matrices of Interactions elements were too large to be read into UCINET, and so covariance matrices (with covariance estimated for respondents) were used as input to the consensus analysis module for the interactions. The covariance model was used in the analysis with the probability of true set at 0.5 . Following Caulkins (2004), the ratio of the first to second eigenvalues ( $=$ the eigenratio) from the factor analysis was interpreted as follows: if the ratio of the first to second factors was $\geq 3$, there was consensus among respondents in relation to that knowledge domain; if the ratio was between 2 and 3 , there was considered to be weak agreement; and if the ratio was $<2$, there was little agreement. When there was consensus, the lack of negative competence scores indicated a good fit to the consensus model. The competence scores represent the relative knowledge of each respondent about the knowledge domain and were the loadings on the first factor of the factor analysis. Competence scores can range from -1 to +1 . Negative competence scores reflect beliefs in opposition to that of the group. When positive, the larger the score, the more that individual knows of the culturally defined truth of the knowledge domain. Consensus analysis enables one to identify answers to three questions of relevance to the work described in this paper (Howowitz 2009): first, whether or not members of a group share a single set of beliefs or values about a domain; second, the degree of concordance of each individual with that shared set of beliefs or values; and third, the culturally correct answers, to the questions posed, for that knowledge domain. We used this latter result to identify what elements were in each group's mental model.

\section{Analytical groups}

Altogether, six groups of respondents formed the basis of the analyses. A first group comprised all the Water Board members (23 persons). A second group comprised 17 stakeholders not involved in the Water Board (non-Water Board) but located in 
Fig. 1. Example of completed representation of an individual mental model elicited with the ARDI method.

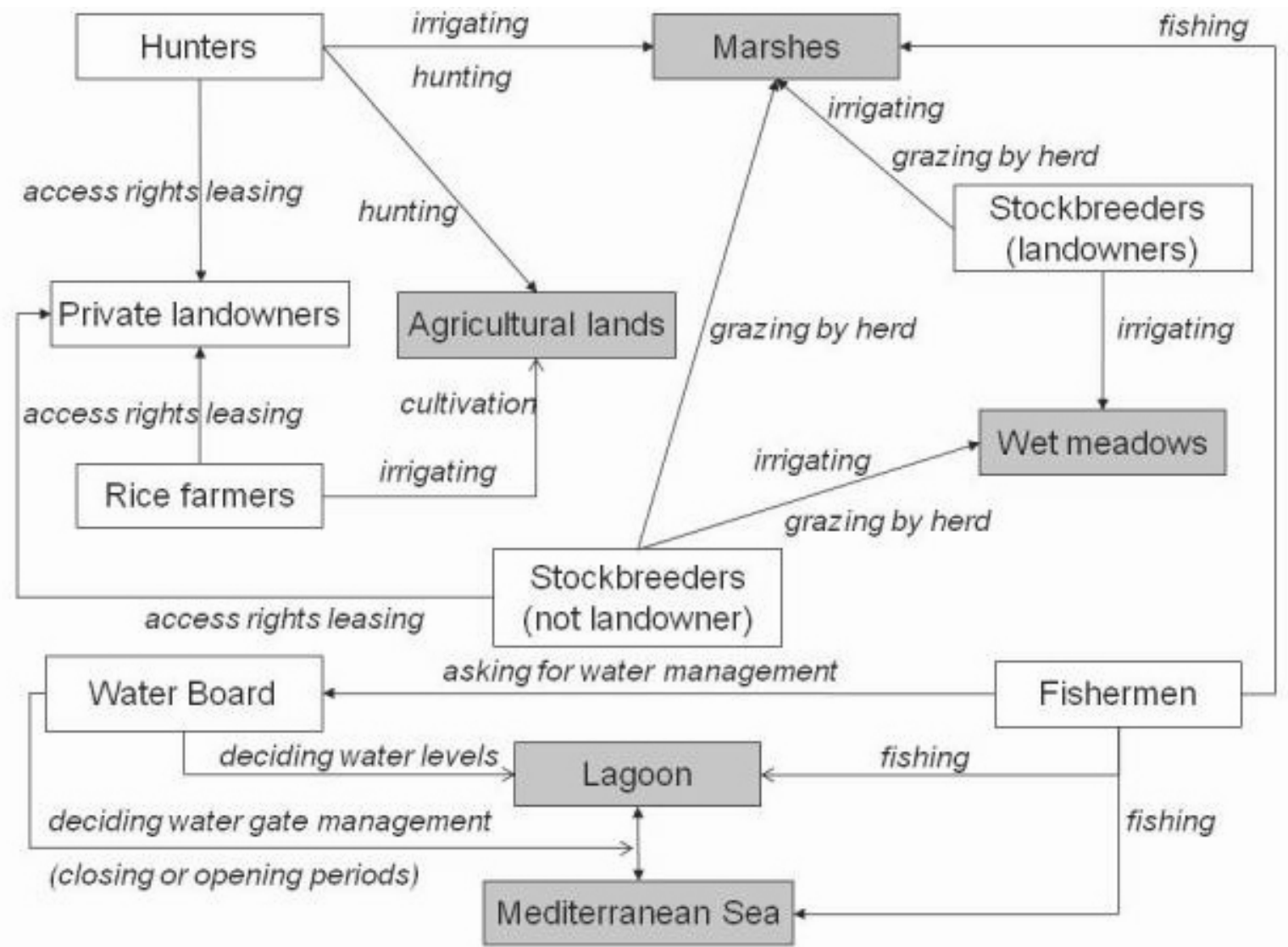

the same drainage networks and practicing similar activities: farming, fishing, hunting, stockbreeding, water, or protected areas management (Table 1). The third group comprised the 12 core members of the Water Board, those who had been frequent attendees of the Water Board meetings for the last 5 years. A fourth group comprised the 11 new members and less frequent attendees of the Water Board meetings (new Water Board). A fifth group comprised the 11 new members of the Water Board and the 17 non-Water Board members for a group of 28 (new Water Board + non-Water Board). A final group included all Water Board and nonWater Board members (i.e., 40 people).

\section{DATA AND RESULTS}

Test of the first prediction: Members of the Water Board have a common representation of the water management system

The data indicated that Water Board members held a common or consensus mental model of the Camargue system (i.e., one including stakeholders, resources, and processes, but excluding interactions) (Table 2). However, the average competence of the Water Board members was not very high (mean = $0.54, \mathrm{SD}=0.22$ ). The Water Board members consensus mental model included 21 of the 64 stakeholders, resources, and processes that were identified by all participants (Table 3). Water Board members did not hold consensus mental models of interactions among elements of the Camargue 
system nor of key stakeholders. For the latter, the eigenratio was greater than three (4.5); however, a single negative competency score suggested that the assumptions of the consensus model may have been violated.

Rice farmers were the most frequently mentioned stakeholder group (mentioned by 22/23 interviewees) followed by managers of protected areas, hunters and fishermen, and then local and government management bodies. The Water Board was mentioned by less than $50 \%$ of the interviewees, but researchers, landowners, and other farmers were rarely mentioned (Fig. 2).

The most frequently listed resources were the irrigation and drainage networks followed by the lagoon, the freshwater coming from the Rhône River, the agricultural lands, and the sea. Animal resources (fish, waterfowl, and cattle) were other commonly identified resources (Fig. 3).

The data indicated that Water Board members were in weak agreement in terms of their mental models of the resources in the Camargue (Table 2). The average competence in relation to that mental model was relatively low $($ mean $=0.54, \mathrm{SD}=0.23)$.

Forty-two percent of the listed processes were ecological ones, $28 \%$ were related to economic processes, and $30 \%$ to social ones. Change in the agricultural system was the most mentioned process (i.e., farming economy changes) followed by change in biophysical conditions: water salt levels, sea and Rhône river floods (Fig. 4).

The data indicated that Water Board members held a consensus mental model of the processes affecting the Camargue (Table 2). The agreed processes of this mental model were salt dynamics (soil and water), water management cost dynamics, rice market changes, flooding dynamics, and global environmental policies changes (national and European).

The number of total interactions identified by Water Board members ranged from 17 to 54 (Fig. 5). Social interactions corresponded to $29 \%$ of the total number of interactions. The data indicated that Water Board members did not hold a consensus mental model of the interactions among elements in the Camargue (Table 2).
We conclude that members of the Water Board held mental models of the Camargue system that were largely shared or common. However, there were elements of the system about which the Water Board members did not have a consensus mental model, in particular, the interactions among stakeholders and resources.

\section{Test of the second prediction: The mental models or representation of the water management system held by members of the Water Board were different from those held by stakeholders not involved in the Water Board}

\section{Is there a shared representation of water management among the stakeholders not involved in the Water Board?}

The data suggested that non-Water Board members held a common or consensus mental model of the Camargue system (Table 2). As with the Water Board members, the average competence of the non-Water Board members was relatively low (mean $=0.51, \mathrm{SD}=0.09)$. The non-Water Board members' consensus mental model included 12 of the 64 stakeholders, resources, and processes that were identified by all participants (Table 3 ).

The non-Water Board group did not have consensus mental models of resources, processes, or interactions (Table 2). Rice farmers were the most frequently mentioned stakeholders followed by stockbreeders, hunters, water management associations, and fishermen (Fig. 2). The Water Board was cited once, and scientists were not cited. Management bodies such as Natural Regional Park, private landowners, and the dykes' management body were rarely cited.

The data suggested that non-Water Board members' mental model of the stakeholders in the Camargue was strongly consensual (Table 2), and their average competence in relation to this mental model was relatively high (mean $=0.71, \mathrm{SD}=0.12$ ). The nonWater Board group's mental model of stakeholders included the syndicate for water management (i.e., the administrative body in charge of the management of irrigation and drainage associations, mixing local and regional authorities and landowners), hunters, municipalities, livestock farmer (bulls), managers of protected areas, fishermen, and rice farmers. 
Table 2. Summary results of the consensus analysis for each sample and subsample. Data are the eigenratios. A value $>3$ indicates that there is consensus between elements of the mental model assuming no negative competence scores. Where the latter existed, the evidence did not support a consensus model. For the "system" analysis, all stakeholder, resources, and processes were included but the interactions data were excluded. WB, Water Board.

\begin{tabular}{|c|c|c|c|c|c|c|}
\hline Theme & $\begin{array}{l}\text { WB } \\
(n=23)\end{array}$ & $\begin{array}{l}\text { Non-WB } \\
(n=17)\end{array}$ & $\begin{array}{l}\text { Core WB } \\
(n=12)\end{array}$ & $\begin{array}{l}\text { WB + non- } \\
\text { WB } \\
(n=40)\end{array}$ & $\begin{array}{l}\text { New WB } \\
(n=11)\end{array}$ & $\begin{array}{l}\text { New WB + } \\
\text { non-WB } \\
(n=28)\end{array}$ \\
\hline Stakeholders & $4.53 \dagger$ & $6.82 \%$ & $4.70 \ddagger$ & $4.48 \dagger$ & $2.27 \dagger$ & $4.55 \dagger$ \\
\hline Resources & $2.99 \S$ & $1.51 \dagger$ & $2.28 \S$ & $2.19 \dagger$ & $2.27 \dagger$ & $2.29 \dagger$ \\
\hline Processes & $3.69 \ddagger$ & $0.77 \dagger$ & $3.64 \ddagger$ & $4.65 \dagger$ & $2.57 \dagger$ & $2.79 \dagger$ \\
\hline Interactions & $1.08 \dagger$ & $1.05 \dagger$ & $1.08 \dagger$ & $1.08 \dagger$ & $1.07 \dagger$ & $1.06 \dagger$ \\
\hline System & $5.87 \ddagger$ & $5.87 \ddagger$ & $6.54 \ddagger$ & $6.08 \ddagger$ & $3.90 \ddagger$ & $5.21 \ddagger$ \\
\hline
\end{tabular}

$\dagger$ Consensus model assumptions violated.

$\ddagger$ Consensus.

$\S$ Weak agreement.

The resources non-Water Board members most frequently cited were freshwater from the Rhône River, agricultural land, and animal resources (Fig. 3). However, the data suggested that the non-Water Board group did not share a mental model of resources in the Camargue (Table 2). Forty-six percent of the processes listed by the non-Water Board members were ecological ones, $30 \%$ related to economic processesh, and $24 \%$ to social processes. The changes in biophysical conditions (water salt levels, marine and Rhône River flooding) were frequently highlighted, followed by changes in farming (market, profitability, land area under farming), water and air pollution, and invasive species in the marshlands (Fig. 4). The data suggested that non-Water Board group members did not, however, have a shared mental model of processes in the Camargue (Table 2). The number of total interactions identified by non-Water Board members ranged from 12 to 33 (Fig. 5). Social interactions accounted for $20 \%$ of the total number of interactions identified. The non-Water Board group did not have a shared mental model of interactions among stakeholders and resources in the Camargue (Table 2).
We conclude that, although the non-Water Board group shared a mental model of the Camargue system, that shared representation was dominated by their strongly shared mental model of stakeholders. Little else in their mental model was common among the group.

\section{Comparison of the Water Board and non-Water Board groups}

Whether or not different stakeholder groups were perceived to be important in water management differed across sample groups. For the Water Board members, local direct stakeholders, such as rice farmers and fishermen, played a key role in the system, but social interactions with state representatives, local authorities, natural regional park manager, and scientists were also important. For the nonmembers, stockbreeders, hunters, fishermen, and farmers played key roles in the water management. Their mental models showed that indirect stakeholders and upper level decision makers were not part of their consensus mental models (Table 3). 
Table 3. Consensus answer key for whole system mental model of the six sample groups: the core Water Board members (core WB), the Water Board members (WB), the new Water Board members (new WB), all respondents together $(\mathrm{WB}+$ non-WB), the new Water Board members and non-Water Board members (new WB + non-WB), and the non-Water Board sample (non-WB). A "1" in each column identifies that stakeholder, resource, or process was included in the consensus mental model of that group, and a "0" indicates that it was not.

\begin{tabular}{|c|c|c|c|c|c|c|}
\hline Stakeholder, resource, process & Core WB & WB & $\begin{array}{l}\text { New } \\
\text { WB }\end{array}$ & $\begin{array}{c}\text { WB } \\
+ \\
\text { non-WB }\end{array}$ & $\begin{array}{c}\text { New WB } \\
+ \\
\text { non-WB }\end{array}$ & Non-WB \\
\hline Syndicate for water management & 1 & 1 & 1 & 1 & 1 & 1 \\
\hline Hunter & 1 & 1 & 1 & 1 & 1 & 1 \\
\hline Livestock farmer (bulls) & 1 & 1 & 1 & 1 & 1 & 1 \\
\hline Managers of protected areas & 1 & 1 & 1 & 1 & 1 & 1 \\
\hline Ponds and lagoons & 1 & 1 & 1 & 1 & 1 & 1 \\
\hline Marshes & 1 & 1 & 1 & 1 & 1 & 1 \\
\hline Mediterranean Sea & 1 & 1 & 1 & 1 & 1 & 1 \\
\hline Fisher & 1 & 1 & 1 & 1 & 1 & 1 \\
\hline Rhône River (fresh water) & 1 & 1 & 1 & 1 & 1 & 1 \\
\hline Rice farmer & 1 & 1 & 1 & 1 & 1 & 1 \\
\hline Arable lands & 1 & 1 & 1 & 1 & 1 & 1 \\
\hline Drainage network & 1 & 1 & 1 & 1 & 0 & 0 \\
\hline Municipalities & 1 & 1 & 1 & 1 & 1 & 0 \\
\hline Salt dynamics (soil and water) & 1 & 1 & 1 & 1 & 1 & 0 \\
\hline Rice market & 1 & 1 & 1 & 1 & 1 & 0 \\
\hline Central government services & 1 & 1 & 1 & 1 & 1 & 0 \\
\hline Irrigation network & 1 & 1 & 1 & 1 & 0 & 0 \\
\hline Natural Regional Park Authority & 1 & 1 & 1 & 1 & 0 & 0 \\
\hline Researcher & 1 & 1 & 0 & 0 & 0 & 0 \\
\hline Flooding dynamics & 1 & 1 & 0 & 0 & 0 & 0 \\
\hline Global environmental policies (national and European) & 1 & 1 & 1 & 0 & 0 & 0 \\
\hline Water Board & 1 & 0 & 0 & 0 & 0 & 0 \\
\hline Water management cost dynamics & 1 & 0 & 0 & 0 & 0 & 0 \\
\hline Birds & 1 & 0 & 0 & 0 & 0 & 0 \\
\hline Fish & 1 & 0 & 0 & 0 & 0 & 0 \\
\hline Salt industry & 1 & 0 & 0 & 0 & 0 & 0 \\
\hline Grasslands & 0 & 0 & 0 & 0 & 1 & 1 \\
\hline
\end{tabular}


Fig. 2. Frequency with which members (WB) and nonmembers (non-WB) of the Water Board listed each of the main stakeholders.

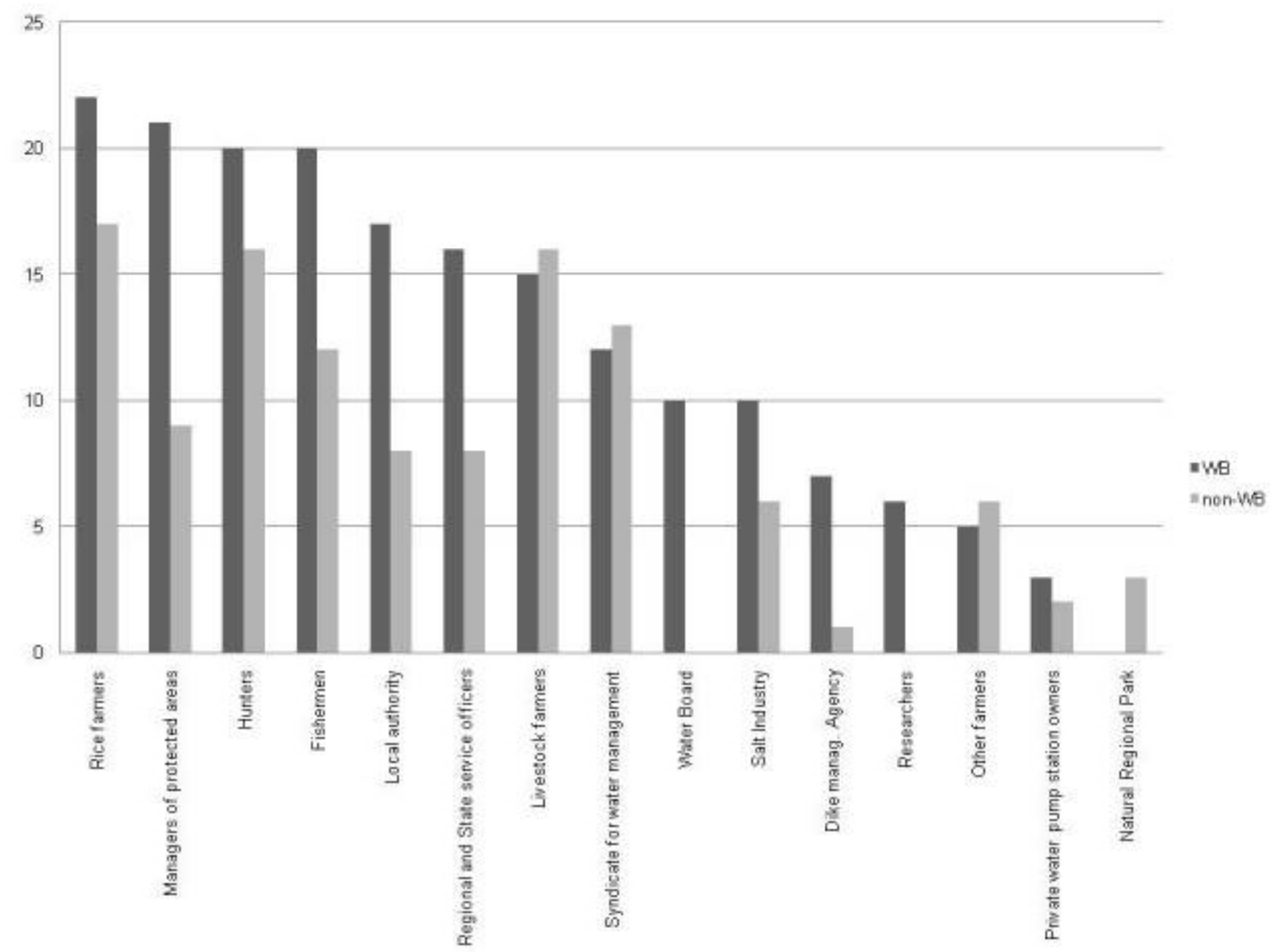

Irrigation and drainage networks were key resources for the Water Board members, whereas the nonmembers focused on freshwater and agricultural land availability. That meant that, for the Water Board, hydraulic components of the water system were fundamental, whereas the water resource itself was the main concern of nonmembers. These differences highlight two different understandings of water management issues.

Ecological processes dominated the mental models of both Water Board and non-Water Board members. However, the nonmembers listed more economic processes, whereas Water Board members gave priority to social processes. A notable difference was that nonmembers listed half the number of processes as Water Board members, and usually listed processes strongly linked with their own activity (i.e., development of invasive species in grazed marshes).

For each theme, we ran the consensus analysis on the Water Board members and non-Water Board members as a combined group (Table 2). The results show that these two groups in combination did share a consensual mental model of the whole system but did not agree on any of the system's constituent parts. The consensual mental model of the system comprised 18 of the 64 stakeholders and resources and processes identified by all participants (Table 3 ). The Water Board members had a richer shared mental model (i.e., with more elements) than did the non-Water Board members, including 21 elements versus the 12 elements included in the non-Water Board group's consensus system mental model (Table 3). 
Fig. 3. Frequency with which members (WB) and nonmembers (non-WB) of the Water Board listed each of the main resources.

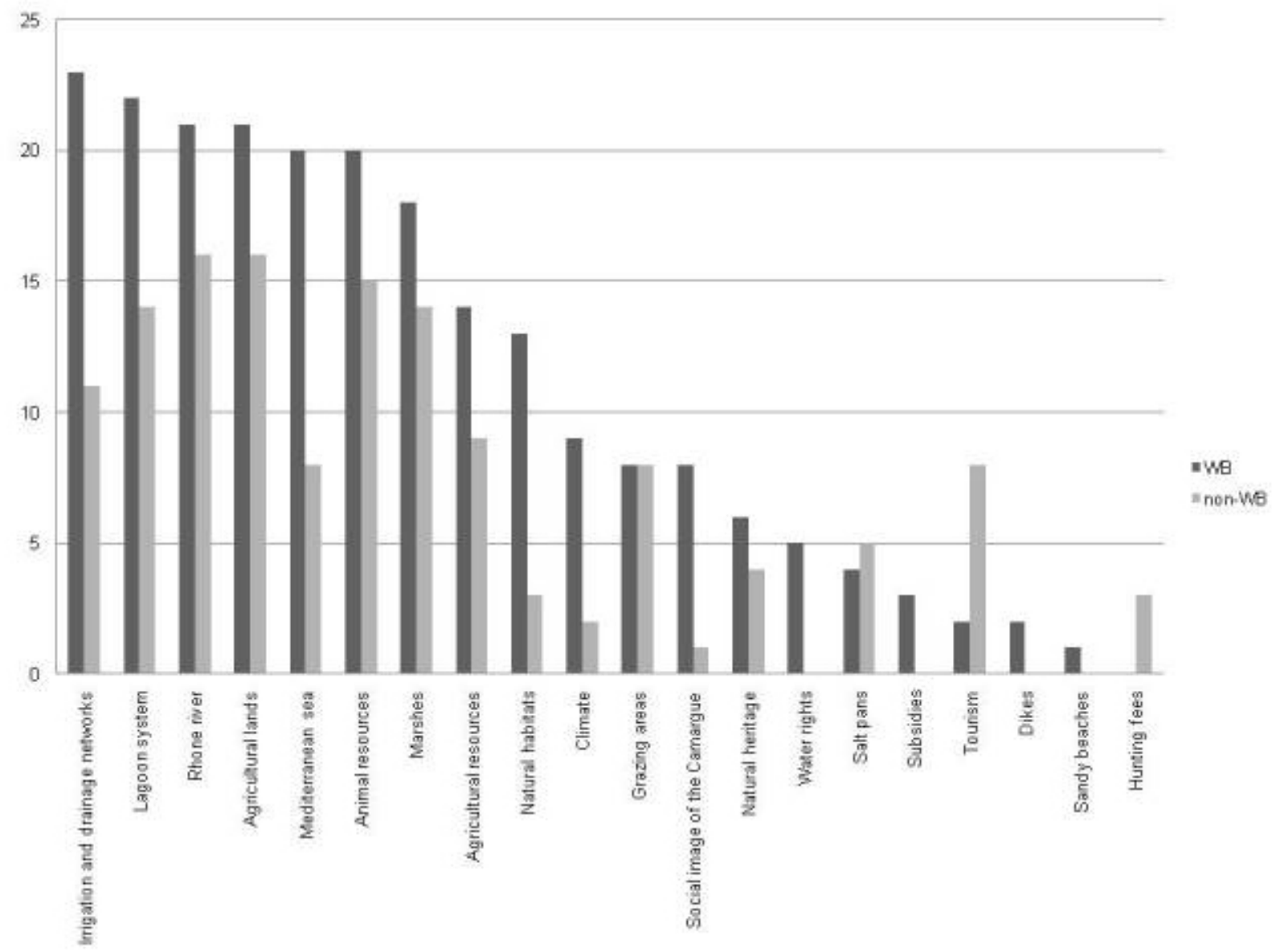

We conclude that the mental models or representations of the water management system held by members of the Water Board were different from those held by stakeholders not involved in the Water Board. We considered then that our second prediction was not falsified.

\section{Test of the third prediction: Groups' mental models converge to a similar one through interaction}

To explore the convergence of mental models through group interaction, we examined the mental models of (1) the 12 core Water Board members; (2) the less frequent attendees to Water Board meetings or new members of the Water Board $(n=$ 11); (3) the new Water Board members together with the non-Water Board members $(n=28)$; and (4) the non-Water Board members $(n=17)$. If the mental models of groups converged through group interaction, then we would expect the following to be true:

1. Core Water Board members would hold consensus mental models with high average competencies in relation to these mental models; new Water Board members' mental models would share elements of the mental models of core Water Board members, but there would not be complete overlap. Their average competence with regard to the shared mental model would be lower than that of the core Water Board members. 
Fig. 4. Frequency with which members (WB) and nonmembers (non-WB) of the Water Board listed each of the main processes.

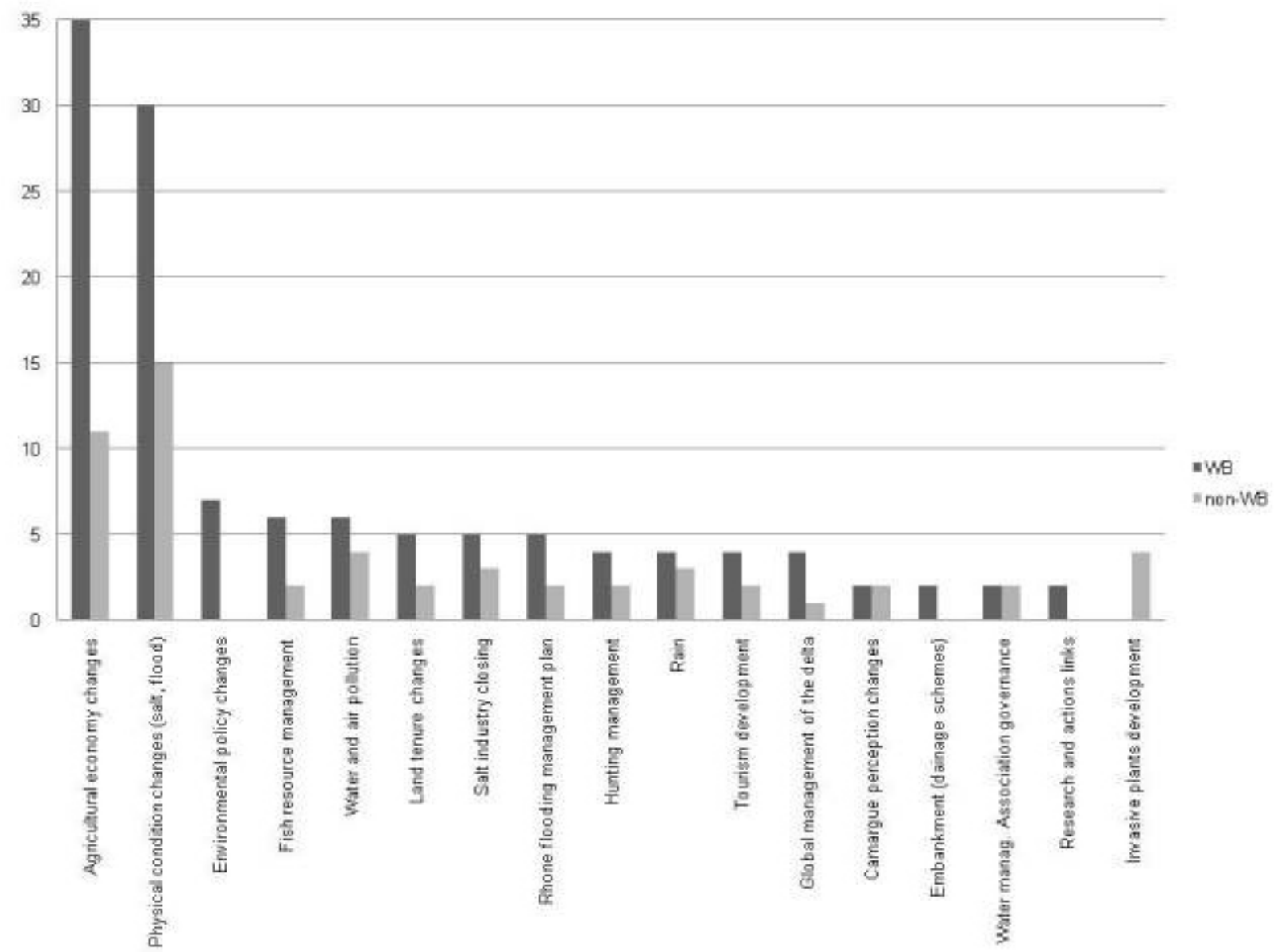

2. New Water Board members' mental models would also share some elements with nonWater Board members. They would be unlikely to share consensus mental models, and their average competencies would be lower than those of the non-Water Board;

3. Non-Water Board respondents would not have the same mental models as the Water Board members. They would be less likely to have consensus mental models.

Overall, competencies were highest for consensus mental models of stakeholders and lowest for consensus mental models of processes (Fig. 6). Thus, members of each group knew, on average, most about stakeholders and least about processes.
Core Water Board members and new Water Board members

Core Water Board members held consensus mental models of stakeholders, processes, and the whole system, had weak agreement on resources, and did not share a consensus mental model of interactions (Table 2). Their competencies in relation to stakeholders $($ mean $=0.59, \mathrm{SD}=0.12)$, resources (mean $=0.55, \mathrm{SD}=0.21)$, processes $($ mean $=0.51$, $\mathrm{SD}=0.18)$, and the whole system $($ mean $=0.55, \mathrm{SD}$ $=0.10$ ) were, however, all relatively low.

The new Water Board members shared a consensus mental model of the whole system, had weak agreement on a mental model of key processes, and did not share mental models of stakeholders, resources, or interactions (Table 2). Their competence in relation to their weakly held mental 
Fig. 5. Violin plots of the number of stakeholders, resources, processes, and interactions identified by members (WB) and by nonmembers of the Water Board. The white dot represents the median value, and the black bar the 20th to 80th percentiles of the data. The different colored ellipses represent the probability density of the data at different values.
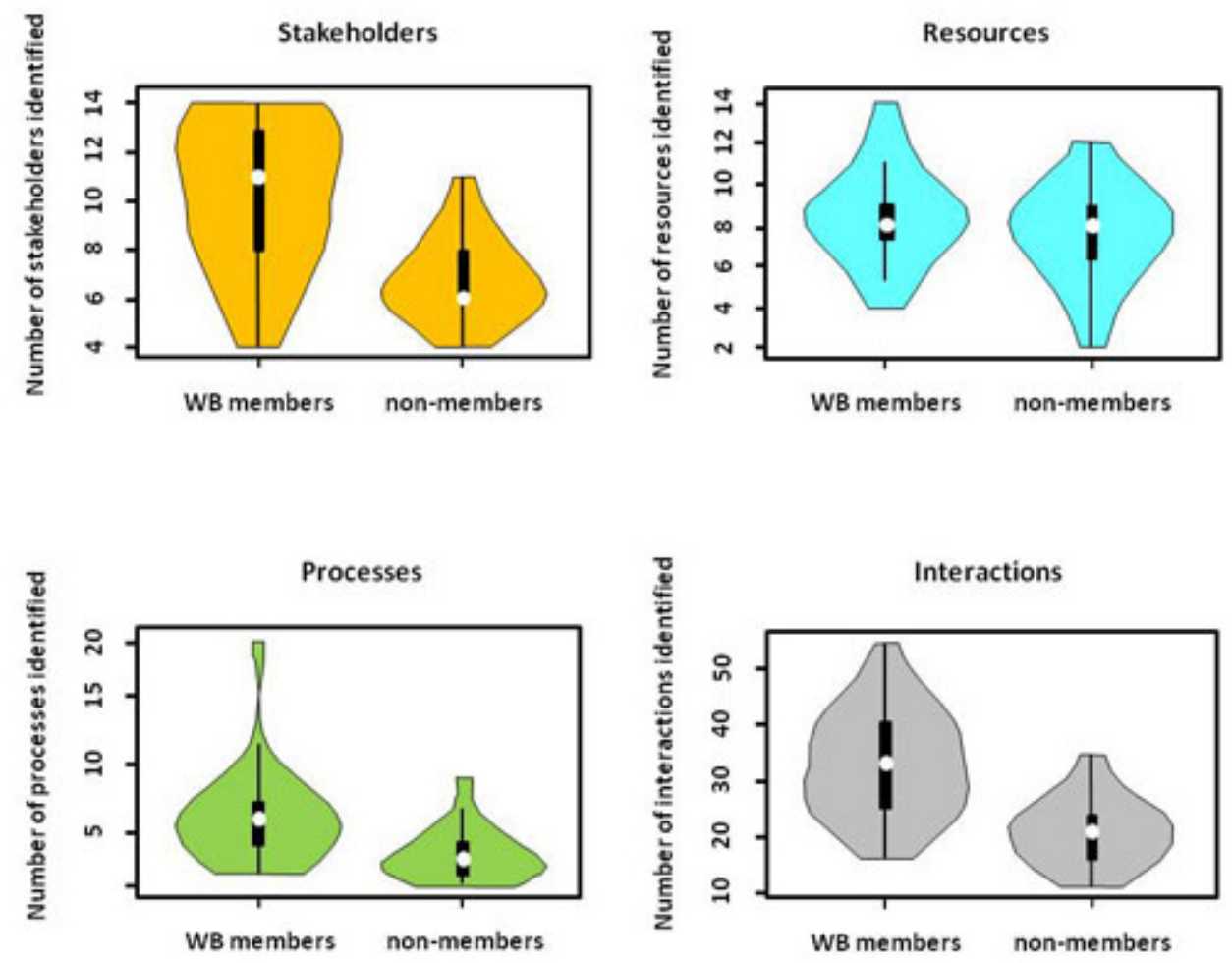

model of processes was low (mean $=0.48, \mathrm{SD}=$ $0.15)$ as was their competence in relation to their whole system mental model (mean $=0.47, \mathrm{SD}=$ $0.18)$. The content of their whole system mental model (Table 3) contained 19 elements in common with the core Water Board mental model. In relation to their respective group's consensus mental models of the whole system, the competencies of the core Water Board and the new Water Board members were about the same (Exact Wilcoxon rank sum test, $\mathrm{W}=92, \mathrm{P}=0.1141)$.

\section{New Water Board members and non-Water Board members}

The content of new Water Board members' whole system mental model contained 11 elements in common with the non-Water Board mental model. Although the new Water Board members and the non-Water Board members did share a consensus mental model of the whole system, they did not have consensus mental models of any of the constituent parts (Table 2). Even if the eigenratio for stakeholders was high, the presence of negative competencies compromised the assumptions of the formal consensus model. The whole system mental model of these two groups reflects perhaps a scale expansion in the model of the system when moving from the non-Water Board to new Water Board members, with the latter including a number of larger scale stakeholders and processes, such as global environmental policies or central government services (Table 3 ). The competencies of new Water Board members and non-Water Board members were also about the same (Exact Wilcoxon rank sum test, $\mathrm{W}=100, \mathrm{P}=0.78$ ).

\section{Water Board members and non-Water Board} members

Non-Water Board members shared with the Water Board members a consensus mental model of the 
Fig. 6. Violin plots of the competence scores for stakeholders, resources, processes, and the whole system across all groups holding consensus mental models (or mental models in which weak agreement was observed). The white dot represents the median value, and the black bar the 20th to 80th percentiles of the data. The light blue ellipses represent the probability density of the data at different values.

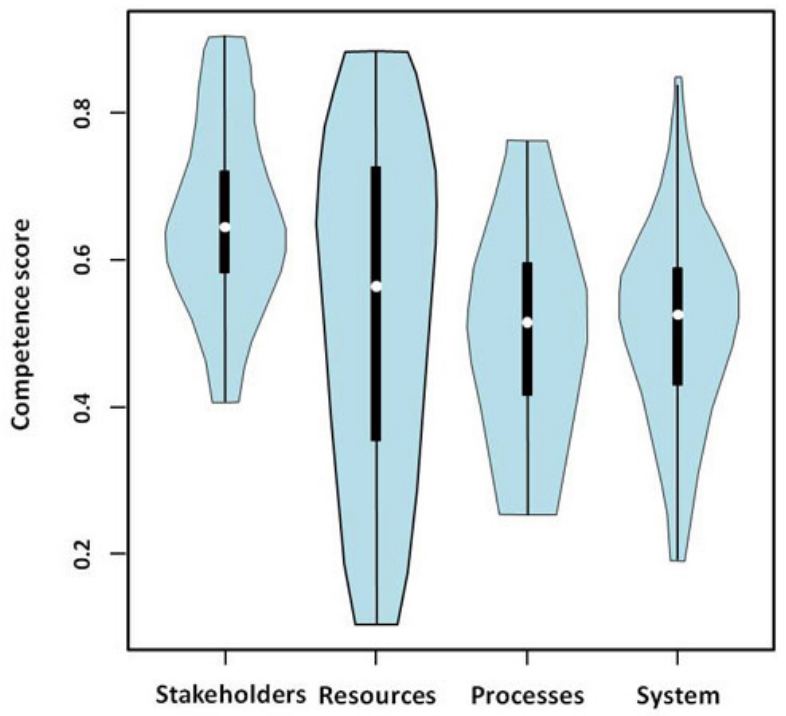

whole system but did not share consensus mental models of any of the constituent parts (Table 2). The overlap in shared elements was small with nonWater Board members' consensus system mental model, including only $57 \%$ of the elements in the Water Board members' consensus model (Table 3). Non-Water Board and Water Board member competencies in relation to their own groups consensus (system) mental models were about the same (Exact Wilcoxon rank sum test, $\mathrm{W}=155.5, \mathrm{P}$ $=0.28)$.

In summary, core Water Board members did hold consensus mental models, but their average competencies in relation to these mental models were not high. New Water Board members' mental models did share elements of the mental models of core Water Board members, and these contained fewer elements with only partial overlap. Their average competence with regard to the shared mental model was not that different from that of the core Water Board members. Thus, our predictions of consensus and overlap were supported but not our predictions of competence.

New Water Board members' mental models did share some elements with non-Water Board members. They did not have the same (consensus) mental models of elements of the system but did have an overall shared mental model. Their average competencies were the same as those of non-Water Board members.

Non-Water Board respondents had the same (consensus) broad mental model as Water Board members, but they did not share the same submodels.

\section{DISCUSSION}

In this section, we discuss the results and highlight several lessons that can be learned from this study in terms of methodology and consequences for the Biosphere Reserve's management.

\section{Methodological issues}

The implementation at the individual level of a method developed to work collectively showed its potential utility (1) when coupled with statistical tools such as Consensus Analysis to elicit and analyze individual mental models, and (2) to facilitate dialogue and collective thinking on a system that stakeholders consider they know well. 
This approach enabled us to test our initial hypothesis and to demonstrate the utility of a mental models approach. Overall, the stakeholders involved in the exercise thought that it was very effective to think about the water management system and to contribute to future concrete decisions. "I really learnt during the exercise that the natural regional park had few capacities to manage the system while I thought before that it was the manager of the water," said a local stakeholder. The ARDI method helps to identify the gap in information on the system functioning and some water uses (i.e., by stockbreeders). "The final interaction diagram allowed me to realize that we have more obligations for dialogue with our partners," said another participant. "I begin to understand why I have not reached my objectives since 30 years," observed another. The ARDI method helps also to address the complexity of the whole system and the necessity to articulate local decisions and global thinking at the level of the whole delta.

\section{Social learning and cooperation issues}

Eliciting mental models was used to compare individual knowledge about the system representation of the management problem. Shared mental models may improve the collective organization and performance (Webber et al. 2000) and thus the adaptive management of natural resources (Berkes et al. 2003). Our results showed how the mental models of the respondents varied in relation to the degree of their involvement in the Water Board (i. e., nonparticipants, new and core Water Board members). Our results showed that a high frequency of social interactions gave rise to higher degree of sharing or overlap in respondent mental models. We present evidence that this occurred for the members of the Water Board. The consequence might be a better coordination among stakeholders involved in this social organization. The data suggested that the Water Board was therefore a learning organization.

Interestingly, the results reflect consensual mental models over stakeholders and either weak or no agreement on processes. We may explain this result by the knowledge level of members; they, on average, knew more about stakeholders and least about processes or interactions. It may be that Water Board meetings provide a forum for learning more about stakeholders than about the water management, as Daniell (2008) underlined in her study on participatory modeling processes. In a work that compared the participants' knowledge before and after co-engineering workshops related to water management, Daniell (2008) found that the majority of participants learned more over the full workshop process about other stakeholders' points of view and relations than about floods and droughts or the impacts of certain flood and drought management options.

Overall, the elicitation of individual mental models revealed that the potential lack of cooperation between the stakeholders would have undesirable consequences. Like Vennix et al. (1996), we observed that, in this way, a more positive attitude toward cooperation was created.

\section{Practical issues related to the Water Board composition, legitimacy, and facilitation}

The results showed that hunters and livestock farmers were frequently listed by participants. Consequently, they seem to be important within the social network, but they are clearly underrepresented in the composition of the Water Board. This result may underline the need to change it.

The Water Board is an informal forum. However, its decisions are increasingly applied by the Water Steering Committee of the Natural Regional Parks. This means that there is a need to change and to think its composition and membership conditions to limit the risk of manipulation by a stakeholder category, such as rice farmers, protected area managers, or fishermen that are increasingly interested in contributing to this forum. Integrating hunters and livestock farmers is a critical issue. Our analyses indicate that they have an important influence on the water decision system at the scale of the estates and wetlands. It will be crucial to find representatives of these two stakeholder groups who are motivated to participate in collective decision making and to provide processes or forums through which these stakeholder groups feel able and willing to participate.

Our results show that the Water Board meetings have promoted greater knowledge and mutual understanding, which are important elements for successful collaboration (Innes 1999, Leach and Pelkey 2001). Social networks and relationships are believed to be key components of social capital (Putman 2000), and knowledge a key component of 
human capital. Shared mental models referred to both capitals, and thus the Water Board appears quite good at building them. These capitals can promote collective action among stakeholders or coordination in partnerships as shown in other studies (Leach et al. 2002). However, members showed little consensus on some components of the mental models, such as processes or interactions. This result may suggest conflicts on core beliefs or core values, such as the relative weight of environmental issues versus economic independence, as shown in other studies for many stakeholders that define their relationship to nature in their watershed of residence (McGinnis 1996). The water board has to address these possible value conflicts that may make consensus building trickier. The absence of cultural consensus or weak agreement on some components of mental models may be linked to the facilitation practice that occurs during the Water Board meetings. Power relationships between scientists, water services, local authorities, and other stakeholders should be addressed to improve collective thinking on the water management system and sharing the different seasonal water levels needs. What may be needed are socially legitimate processes (where legitimacy must be acknowledged across all stakeholder groups) through which key stakeholder groups (hopefully represented on the Water Board) can learn and collectively agree on what are the key processes affecting the overall system and its constituent parts. This is likely to be an important precursor to the development of consensually based management strategies that are effective in achieving collectively agreed upon goals.

\section{CONCLUSIONS}

To improve our understanding of shared knowledge in collective water management or management team design and process enhancements, exploring how mental models were similar among the members of a specific management organization might be useful.

Use of the ARDI method with individuals provided useful data that, when analyzed with consensus analysis tools, enabled us to test our hypothesis and to demonstrate the utility of a mental models approach. We described the individual mental models of the Water Board members and compared them with nonmember mental models in order to verify whether the Water Board is an arena of social learning on water management on the central delta. The results showed that (1) the core Water Board members hold consensus mental models; (2) new Water Board members' mental models shared elements of the mental models of core Water Board members, but there is no complete overlap; (3) new Water Board members' mental models also shared some elements with non-Water Board members; and (iv) non-Water Board respondents did not have the same mental models as the Water Board members.

Our results suggest that a high frequency of interactions within the Water Board give rise to higher degree of sharing of the individuals' mental models. The consequence might be a better coordination among stakeholders. Nevertheless, it appeared that members of the Water Board had learned more about other participants in the group during meetings rather than about the processes or relationships of the Camargue system itself. The absence of cultural consensus or weak agreement on some components of their mental models seems to be linked to the facilitation practice that occurs during the Water Board's meetings. Power relationships between stakeholders should be addressed in greater depth to improve collective thinking on the water management system and sharing the different seasonal water levels requirements.

Responses to this article can be read online at: http://www.ecologyandsociety.org/voll6/iss 1/art43/ responses/

\section{Acknowledgments:}

We would like to thank all stakeholders for participating in this study. This work took place in the GIZCAM project and was conducted with financial support from the French Ministry of Ecology (LITEAU II program) and the SETER Project supported by the Agropolis Fondation.

\section{LITERATURE CITED}

Argyris, C. 1993. Knowledge for action. A guide to overcoming barriers to organizational change. Jossey Bass, San Francisco, California, USA. 
Argyris, C., and D. Schön. 1978. Organizational learning: a theory of action perspective. AddisonWesley, Reading, Massachusetts, USA.

Argyris, C., and D. Schön. 1996. Organizational learning II: theory, method and practice. AddisonWesley, Reading, Massachusetts, USA.

Bandura, A. 1971. Social learning theory. Motivational trends in society. General Learning Press, Morristown, New Jersey, USA.

Beierle, T. C., and J. Cayford. 2002. Democracy in practice. Public participation in environmental decisions. Resources for the Future Press, Washington, D.C., USA.

Beierle, T. C., and D. M. Konisky. 2000. Values, conflict, and trust in participatory environmental planning. Journal for Policy Analysis and Management 19(4):587-602.

Berkes, F., J. Colding, and C. Folke, editors. 2003. Navigating social-ecological systems: building resilience for complexity and change. University Press, Cambridge, UK.

Brown, J. S., A. Collins, and P. Duguid. 1989. Situated cognition and the culture of learning. Educational Researcher 18(1):32-42.

Calvet, C. 2008. Analyse sociale de la gestion de l'eau dans l'île de Camargue: approche par la méthode ARDI. ESITPA Rouen, CEFE CNRS, Montpellier, France.

Cannon-Bowers, J. A., E. Salas, and S. A. Converse. 1993. Shared mental models in expert team decision making. Pages 221-246 in N. J. Castellan, editor. Individual and group decision making. Lawrence Erlbaum Associates, Hillsdale, New Jersey, USA.

Caulkins, D. 2004. Identifying culture as a threshold of shared knowledge: a consensus analysis method. International Journal of Cross Cultural Management 4(3):317-333.

ComMod. 2006. Modélisation d'accompagnement. Pages 217-228 in F. Amblard and D. Phan, editors. Modélisation et simulation multi-agents: application aux sciences de l'homme et de la société. Hermes Sciences, London, UK.
Daniell, K. A. 2008. Co-engineering participatory modelling processes for water planning and management (2 volumes). Dissertation. Australian National University, Canberra, Australia and AgroParisTech, Montpellier, France.

Daré, J. P. 1985. La parole et la technique, l'univers de pensée des éleveurs du Ternois. L'Harmattan, Paris, France.

Doise, W. 1985. Les représentations sociales: définition d'un concept. Connexions 45:243-253.

Doyle, J. K., and D. N. Ford. 1998. Mental models concepts for system dynamics research. System Dynamics Review 14:3-30.

Dray, A., P. Perez, N. Jones, C. Le Page, P. D'Aquino, I. White, and T. Auatabu. 2006. The AtollGame experience: from knowledge engineering to a computer-assisted role playing game. Journal of Artificial Societies and Social Simulations 9(1):6.

Eden, C. 1994. Cognitive mapping and problem structuring for system dynamics model building. System Dynamics Review 10:257-276.

Etienne, M. 2009. Co-construction d'un modèle d'accompagnement selon la méthode ARDI: guide méthodologique. COMMOD, INRA, Avignon, France.

Etienne, M., D. R. Du Toit, and S. Pollard. 2011. ARDI: a co-construction method for participatory modeling in natural resources management. Ecology and Society 16(1):44. [online] URL: http:/ /www.ecologyandsociety.org/vol16/iss 1/art44/.

Gray, B. 2004. Strong opposition: frame-based resistance to collaboration. Journal of Community and Applied Social Psychology 14:166-176.

Gumuchian, H. 1991. Représentations et aménagement $d u$ territoire. Economica, Paris, France.

Habermas, J. 1979. Communication and the evolution of society. Beacon Press, Boston, Massachusetts, USA.

Hare, M. P., and C. Pahl-Wostl. 2002. Stakeholder categorisation in participatory integrated assessment processes. Integrated Assessment 3:50-62. 
Hodgson, A. M. 1992. Hexagons for systems thinking. European Journal of Operational Research 59:220-230.

Horowitz, D. M. 2009. A review of consensus analysis methods in consumer culture, organizational culture and national culture research. Consumption Markets \& Culture 12(1):47-64.

Innes, J. E. 1999. Evaluating consensus building. Pages 631-675 in L. Susskind, S. McKearnan, and J. Thomas-Larmer, editors. The consensus building handbook: a comprehensive guide to reaching agreement. Sage, Thousand Oaks, California, USA.

Innes, J. E., and D. E. Booher. 1999. Consensus building and complex adaptive systems: a framework for evaluating collaborative planning. Journal of the American Planning Association 65:412-423.

Jodelet, S. 2003. Les représentations sociales. Seventh edition. Presses Universitaires de France, Paris, France.

Johnson-Laird, P. N. 1983. Mental models: towards a cognitive science of language, inference, and consciousness. Harvard University Press, Cambridge, Massachusetts, USA.

Jones, N. A., H. Ross, T. Lynam, P. Perez, and A. Leitch. 2011. Mental models: an interdisciplinary synthesis of theory and methods. Ecology and Society 16(1):46. [online] URL: http://www.ecolog yandsociety.org/vol16/iss1/art46/.

Klimoski, R., and S. Mohammed. 1994. Team mental model: construct or metaphor? Journal of Management 20(2):403-437.

Kolmann, M. J., M. Kok, and A. van der Veen. 2005. Mental model mapping as a new tool to analyse the use of information in decision-making in integrated water management. Physics and Chemistry of the Earth 30:317-332.

Lave, J., and E. Wenger. 1999. Situated learning: legitimate peripheral participation. Cambridge University Press, Cambridge, UK.

Leach, W. D., and N. W. Pelkey. 2001. Making watershed partnerships work: a review of the empirical literature. Journal of Water Resources Planning and Management 127:378-385.
Leach, W. D., N. W. Pelkey, and P. A. Sabatier. 2002. Stakeholder partnerships as collaborative policymaking: evaluation criteria applied to watershed management in California and Washington. Journal of Policy Analysis and Management 21(4):645-670.

Mathieu, J. E., T. S. Heffner, G. F. Goodwin, E. Salas, and J. A. Cannon-Bowers. 2000. The influence of shared mental models on team process and performance. Journal of Applied Psychology 85:273-283.

McGinnis, M. V. 1996. Deep ecology and the foundations of restoration. Inquiry-An Interdisciplinary Journal of Philosophy 39:203-217.

Mohammed, S., R. J. Klimoski, and J. R. Rentsch. 2000. The measurement of team mental models: we have no shared schema. Organizational Research Methods 3:123-165.

Moscovici, S. 1961. La psychanalyse son image et son public. Presses Universitaires de France, Paris, France.

Pahl-Wostl, C. 2006. The importance of social learning in restoring the multifunctionality of rivers and floodplains. Ecology and Society 11(1):10. [online] URL: http://www.ecologyandsociety.org/vol11/ iss $1 / \operatorname{art} 10 /$.

Pahl-Wostl, C., and M. Hare. 2004. Processes of social learning in integrated resource management. Journal of Community and Applied Social Psychology 14:193-206.

Pretty, J. 2003. Social capital and the collective management of resources. Science 302:1912-1915.

Putnam, R. D. 2000. Bowling alone: the collapse and revival of American community. Simon \& Schuster, New York, New York, USA.

Romney, A. K., S. C. Weller, and W. H. Batchelder. 1986. Culture as consensus: a theory of culture and informant accuracy. American Anthropologists 88 (2):313-338.

Rouse, W. B., and N. M. Morris. 1986. On looking into the black box: prospects and limits in the search for mental models. Psychological Bulletin 100:349-363. 
Sterman, J. D. 2000. Business dynamics: system thinking and modeling for a complex world. McGraw-Hill, New York, New York, USA.

Vennix, J. 1999. Group model-building: tackling messy problems. System Dynamics Review 15:379-401.

Vennix, J. A. M., H. A. Akkermans, and E. A. J. A. Rouwette. 1996. Group model-building to facilitate organizational change: an exploratory study. System Dynamics Review 12(1):39-58.

Watkins, K., and V. Marsick. 1992. Building the learning organization: a new role for human resource developers. Studies in Continuing Education 14(2):115-129.

Webber, S. S., G. Chen, S. C. Payne, S. M. Marsh, and S. J. Zaccaro. 2000. Enhancing team mental model measurement with performance appraisal practices. Organizational Research Methods 3 (4):307-322.

Webler, T., H. G. Kastenholz, and O. Renn. 1995. Public participation in impact assessment: a social learning perspective. Environmental Impact Assessment Review 15:443-463.

Weller, S. C., and A. K. Romney. 1988. Systematic data collection. Sage, Beverly Hills, California, USA.

Wynne, B. 1992. Risk and social learning: reification to engagement. Pages 275-297 in S. Krimsky and D. Golding, editors. Social theories of risk. Praeger, Westport, Connecticut, USA. 
APPENDIX 1. The case study.

The Camargue is the Rhone river delta on the French Mediterranean coast. The delta covers approximately 150000 ha and is a mosaic of fresh, brackish and saline wetlands interspersed with areas of intensive agriculture and industry (Mathevet 2004). It is a wetland of international importance for its diversity of ecosystems and its wildlife (Heath and Evans 2000). The "Camargue island" is the central part of the delta and constitutes the main part of the Natural Regional Park (75 000 ha, http://www.parccamargue.fr) and Biosphere Reserve. Rice and wheat farming are the most widespread crops in the delta, with the alternative crops being limited by soil salinity (Barbier and Mouret 1992). In 2006, crop lands represented $27 \%$ of the Natural Regional Park while natural habitats represented 54\%, salt pans $18 \%$ and urbanized area $1 \%$. In the central part of the Camargue island a lagoon system consists of the Vaccares lagoon (6600 ha) that is the National Nature Reserve of Camargue, and several smallest lagoons and halophytic scrublands (4500 ha). Under the current wind, marine and rainfall regimes, the water flows between these lagoons and the sea (Chauvelon 1996). The water exchange occurs through a controlled water gate. The management of this flood gate is based on water and salinity objectives and related to fish migrations.

The present irrigation and drainage system was mainly developed during the 19th and first part of the 20th century. The management of the irrigation water generates conflicts between landowners linked to their location in the network and the seasonal availability of water. Several associations manage the runoff, the ground water and the discharge coming from the rice fields. Either the water is pumped back to the Rhone River or it is evacuated by gravity to the lagoon system before it flows to the sea. The evacuation of the water towards the lagoon system still generates problems of water quality and quantity. This situation can generate conflicts mostly between the manager of the National Nature Reserve, rice farmers and fishermen (Picon 1988).

Following the catastrophic floods of 1993 and 1994, local stakeholders decided to create a negotiation forum where a deliberative process between managers, local authorities, and other stakeholders could take place. This Water Board was established to help identify potential trade-offs and actions for water management of the central lagoon system. It is currently made up of 23 members representing the most dominant local activities and administrative bodies with management responsibilities (Table 1). Its president is the water officer of the Regional Agricultural Service and the facilitator is the water management officer of the Natural Regional Park. This Water Board is an informal structure with no legal mandate. It aims to provide an operational space to aid management decisions related the protection of goods and persons from floods, the maintenance of local economic activities and the conservation of natural heritage. The outputs of regular meetings are decisions on water management and the evaluation of their impacts on salt levels of the lagoon system. During flood events the Water Board members meet to suggest and develop operational solutions to local and national authorities in charge of flood management of the delta.

The seasonal variability and unpredictability of the Mediterranean climate generates a high level of uncertainty in the behaviour of the Camargue Island system. To manage this uncertainty the Water Board needs to improve its understanding of the system functions. For that purpose, monitoring and modelling of the system was developed by ecologists and hydrologists (Chauvelon 2001a, 2001b). Social studies complemented these physical scientific studies in order to understand and improve the region's decision-making process (Picon 1988, Mathevet 2004, Dervieux et al. 2006).

\section{REFERENCES}

Barbier, J.M., and J.C., Mouret. 1992. La riziculture et la Camargue. Histoire et recherche. INRA mensuel 64/65:39-51.

Chauvelon, P. 1996. Hydrologie quantitative d'une zone humide méditerranéenne aménagée : le bassin 
du Fumemorte en Grande Camargue, delta du Rhône. PhD thesis, Montpellier II University, France. Chauvelon, P., Sandoz, A., Heurteaux, V., Berceaux, A. 2001a. Satellite remote sensing and GIS used to quantify water input for rice cultivation (Rhône delta, France). Remote Sensing and Hydrology 2000. Proceedings of a symposium held at Santa Fe, New Mexico, April 2000. Edited by M. Owe, K. Brubaker, J. Ritchie \& A. Rango. IAHS Publ.267:446-450.

Chauvelon, P. Tournoud, M.G., Sandoz, A., Berceaux, A., Heurteaux, V., 2001b. Modélisation du fonctionnement hydrologique d'un hydrosystème côtier méditerranéen fortement anthropisé: l'Ile de Camargue. UNESCO, PHI-V/ Documents techniques en hydrologie 51:217-224.

Dervieux, A., Jolly, G., Allouche, A. 2006. Gestion de 1'eau et projet de territoire : vers une gestion intégrée du delta du Rhône. VertigO - La revue en sciences de l'environnement, Vol7no3. [online] URL: www.vertigo.uqam.ca/vol7no3/framerevue.html

Heath, M.F., and M.I. Evans. 2000. Important bird areas in Europe: Priority sites for conservation. 2 vols. BirdLife International, Cambridge, UK.

Mathevet, R. 2004. Camargue incertaine. Sciences, usages et natures. Buchet-Chastel, Paris, France. Picon, B., 1988. L'espace et le temps en Camargue. Actes Sud, Arles, France. 